\title{
Effect of Humidity on the Physical Properties of Aspirin Tablets Produced By Melt Granulation and Slugging Methods
}

\author{
*John A. Avbunudiogba ${ }^{1}$, Omonyemen E. Cash-Torunarigha ${ }^{2}$ and \\ Ikechukwu Onah ${ }^{1}$ \\ 1Department of Pharmaceutics and Industrial Pharmacy, Faculty of Pharmacy, Delta State University, Abraka, \\ Delta State, Nigeria \\ 2 Department of Pharmaceutics and Pharmaceutical Technology, Faculty of Pharmacy, University of Benin, \\ Benin City, Nigeria
}

\begin{abstract}
Aspirin is easily hydrolyzed by water and it is therefore produced by slugging, which is a time consuming process. This work was aimed at studying the effect of humidity on the physical properties of aspirin tablets produced by melt granulation in comparison with conventionally produced aspirin tablets. Goat fat (1 to $2 \% \mathrm{w} / \mathrm{w})$ and carnauba wax (2 to $7.5 \% \mathrm{w} / \mathrm{w})$ were the waxes used as granulating agents in the melt granulation technique. The granules were characterized and the ones with adequate flow were compressed to tablets of diameter $13.8 \pm 0.1 \mathrm{~mm}$ and thickness $3.2 \pm 0.1 \mathrm{~mm}$ using a single punch tableting machine. Resulting tablets were evaluated and then stored under ambient humidity and $1 \%$ relative humidity and the effect of the storage on the physical properties of the tablets were analyzed monthly for two months duration. The bulk and tapped densities of the granules were between the ranges of $0.62 \pm 0.00-0.71 \pm 0.01 \mathrm{~g} / \mathrm{cm}^{3}$ and $0.77 \pm 0.02-0.85 \pm$ $0.00 \mathrm{~g} / \mathrm{cm}^{3}$ respectively. The angle of repose ranged from $26.96 \pm 0.07^{\circ}-39.21 \pm 0.02^{\circ}$, Carr's index between $10.34 \pm 0.14$ and $21.88 \pm 0.01$ and Hausner's ratio being in the range of $1.12 \pm 0.05-1.28 \pm 0.11$. The resulting tablets displayed a good disintegration, having disintegration time ranging from $2.28 \pm 0.12-5.30 \pm 0.13 \mathrm{~min}$. Tablet friability and tensile strength ranged from $1.09 \pm 0.05-3.10 \pm 0.01 \%$ and $0.02 \pm 0.01-0.07 \pm 0.00$ $M \mathrm{Mm}^{-2}$ respectively. After storage there was no change in tensile strength, however, there was a change in disintegration time and friability ranging from $0.46 \pm 0.05-5.50 \pm 0.08$ min and $1.25 \pm 0.01-3.50 \pm 0.10 \%$ respectively. Melt granulation, which is a simpler method, had the least influence of humidity on the physical properties of aspirin tablets.
\end{abstract}

Keywords: Aspirin, Humidity, Melt granulation, Physical properties, Slugging and Waxes.

\section{Introduction}

Aspirin (Acetyl salicylic acid) is a drug commonly used as an analgesic, antipyretic and antiinflammatory. It is also used in low doses to help prevent heart attack and stroke [1][2]. There are new evidences, which suggest the action of aspirin in cancer prevention, especially colorectal cancer [3][4]. However, aspirin is faced with a major challenge of being hygroscopic. It absorbs moisture from the atmosphere easily and this leads to its degradation into acetic acid and salicylic acid. Due to this major challenge, aspirin cannot be produced by wet granulation technique and so slugging is the method employed in its production. Slugging is however faced with some challenges, which include it being time consuming, expensive, production of more dust or fines, which can be harmful to both the operators and the environment.

Melt granulation is a technique in which the drug powder is triturated with melted wax or fat and then screened to form granules [5][6][7]. The waxes which serve as binders are of low melting point [8][9]. Waxes are hydrophobic materials and could be natural or synthetic in origin. The naturally occurring waxes could be of animal origin such as goat fat, or of plant origin such as carnauba wax. Goat fat is normally extracted from the adipose tissues in the peritoneum of sacrificed goat. It has a melting point of $55-59^{\circ} \mathrm{C}$. Carnauba wax is also known as Brazil wax and palm wax. It is obtained from the leaves of the palm, Copernicia prunifera, grown in Northeastern Brazilian states. It has a melting point of $82-86^{\circ} \mathrm{C}$. Melt granulation possesses some advantages: it is less time and energy consuming [10], there is a uniform dispersion of fines and there is no risk of residual solvents since solvents are not used as granulating agents [11]. More importantly, hydrolytic degradation is averted. However, moisture can be absorbed by drugs in storage and use; the amount of moisture absorbed by drugs or excipients is known to influence their physical stability, such as: hardness, disintegration of compacts or the dissolution rate of the drugs [12].

In the present study, we investigate the properties of aspirin tablets produced by melt granulation and also to study the influence of humidity on the tablets physical properties, in comparison with aspirin tablets produced by slugging. 


\subsection{Materials}

\section{Materials and Methods}

Acetyl salicylic acid powder (BDH, Poole, UK), carnauba wax (Hale wood Chemicals Ltd, England), goat fat, maize starch (BDH, Poole, UK), talc (BP grade), magnesium stereate (BP grade). All other reagents used were of analytical grade and used without further purification.

\subsection{Methods}

\subsubsection{Extraction and purification of goat fat}

The fatty tissues which are normally discarded from the peritoneum of sacrificed goat (Capra hircus) were collected from an abattoir in Benin City, Edo State, Nigeria, They were washed and sliced into smaller pieces. These pieces were put into a $2 \mathrm{~L}$ stainless steel jar and heated for $30 \mathrm{~min}$. The melted fat which was amber coloured, was then heated under reflux with activated charcoal for $1 \mathrm{~h} \mathrm{in}$ order to remove impurities and odour. The fat was then filtered hot, allowed to solidify and stored [7]

\subsubsection{Granulation techniques}

a. Dry granulation

A mixture of Aspirin powder $(50 \mathrm{~g})$ with maize starch $(6 \% \mathrm{w} / \mathrm{w})$ was compressed into slugs with the use of a Manesty single punch tableting machine, at an arbitrary load unit of 45 . The slugs were broken down into granules and passed through a sieve of $710 \mu \mathrm{m}$ aperture.

b. Melt granulation

Aspirin powder $\left(50 \mathrm{~g}\right.$ ) was added to melted wax (carnauba wax at $82-88^{\circ} \mathrm{C}$, goat fat at $55-59^{\circ} \mathrm{C}$ ) and homogenously mixed. The mixture was cooled and forced through a sieve ( $710 \mu \mathrm{m}$ aperture). The resultant granules were dried in an air conditioned room and then stored in a desiccator prior to characterization. The procedure was repeated at concentrations 3,5 and $7.5 \% \mathrm{w} / \mathrm{w}$ (carnauba wax) and 1 and $2 \% \mathrm{w} / \mathrm{w}$ (goat fat).

\subsubsection{Granules characterization}

Angle of repose was analyzed by using the fixed funnel method as described by Okoye et al [13]; the bulk and tapped densities were determined as previously described by Onyekweli [14]. The compressibility indices and the Hausner's ratios were computed from the values obtained from the bulk and tapped densities.

\subsubsection{Granules compression}

Magnesium stearate and talc $(1 \% \mathrm{w} / \mathrm{w}$ each) were mixed with the aspirin granules prior to tableting. Aspirin tablets were formed at a compression load of 30 arbitrary units on the load scale by a single punch tableting machine (type F3, Manesty, Liverpool, UK).

\subsubsection{Evaluation}

Tablet friability was determined with the use of a Veego tablet friabilator, which was run at $25 \mathrm{rpm}$ for 4 min. Ten tablets of each batch were randomly selected and analyzed.

In computing the tensile strength of the tablets, the hardness of the tablets was first determined using a Monsanto hardness tester to cause a diametral compression. Tablet dimension was also determined with the use of a micrometer screw gauge.

Tablet disintegration test was carried out in a Manesty disintegration apparatus. Distilled water maintained at 37 $\pm 2.0^{\circ} \mathrm{C}$ was used as the disintegration medium. Six randomly selected tablets from each batch were analyzed.

\subsubsection{Dissolution test}

This was done with the use of a rotating basket dissolution apparatus. The dissolution medium used was distilled water $(900 \mathrm{ml})$ maintained at $37 \pm 2.0^{\circ} \mathrm{C}$. At predetermined time intervals, $5 \mathrm{ml}$ of leaching fluid was withdrawn and immediately replaced with fresh dissolution medium maintained at same temperature. The withdrawn samples were filtered and analyzed with the use of a UV spectrophotometer (PG Instrument, USA) at absorbance wavelength of $264 \mathrm{~nm}$.

\subsubsection{Tablet evaluation after storage}

The weights of some tablets of each batch were determined and the mean weight obtained recorded. The tablets were stored under ambient humidity and $1 \%$ relative humidity (RH $1 \%$,). To obtain RH $1 \%$, a glass chamber was charged with dried silica gel.

Tablets were removed from storage and the physical properties (friability, tensile strength and disintegration time) were evaluated at one month interval for possible change in physical properties. 


\subsubsection{Statistical analysis}

Experiments were performed in triplicates and the data were expressed as mean \pm standard deviation. The data were statistically analyzed by the student $t$-test and level of significance was set at $p<0.05$

\section{Results and Discussion}

There was a gradual decrease in the values of the flow and packing properties of granules prepared with carnauba wax as the wax concentration increased (TABLE 1). However, an increase in the Hausner's ratio was observed at 5\% carnauba wax concentration. For granules prepared with goat fat an increase in concentration caused a decrease in bulk and tapped densities and also Carr's index, but an increase in angle of repose and Hausner's ratio. However, the differences induced by the concentration strength for both carnauba wax and goat fat were not statistically significant. Also granules prepared by slugging displayed comparable flow and packing properties with those prepared by melt granulation (TABLE 1).

None of the tablets met with the USP specification of $1 \%$ for friability. Tablets produced by slugging possessed the least friability (1.09\%). It was observed that tablets containing goat fat would not be able to withstand shock and abrasion as much as the other tablets because they possessed the highest friability values of 3.08 and $3.10 \%$. The friability of tablets produced by melt granulation using carnauba wax $(5 \& 7.5 \%)$ was comparable with those prepared by the conventional slugging method (TABLE 2). Tensile strength for all the tablets was within the range of $0.02-0.07 \mathrm{MNm}^{-2}$ (TABLE 2). All tablets irrespective of type of wax or formulation method, disintegrated within $5.30 \mathrm{~min}$, which was within the BP specified time of $15 \mathrm{~min}$. However, it was observed that while the disintegration time for tablets containing goat fat increased as the wax concentration increased, those containing carnauba wax decreases with an increase in the wax concentration (TABLE 2).

In the dissolution profile of the tablets, it was observed that at $1 \%$ goat fat concentration, $100 \%$ of the drug content was released within $40 \mathrm{~min}$, while within the same time duration $99 \%$ release was observed for $2 \%$ $\mathrm{w} / \mathrm{w}$ goat fat. Tablets containing carnauba wax displayed an increase in drug release with corresponding increase in concentration of the wax. Within $60 \mathrm{~min}, 84 \%$ drug was released from tablets containing $2 \%$ carnauba wax, while $96 \%$ drug release was observed from tablets containing 3\% carnauba wax. At $7.5 \%$ carnauba wax concentration, $100 \%$ of the drug was released within $40 \mathrm{~min}$. this observation was the same for conventional tablets. Tablets produced by melt granulation using either goat fat or carnauba wax (at $7.5 \%$ ) were comparable with the dissolution profile obtained from the slugged (conventional) tablets. However, irrespective of the formulation technique, type and concentration of wax, all the tablets met the BP specification for dissolution profile for immediate release tablets (Fig 1 and 2).

Tablets physical properties were found to have being affected after storage in different humidity types for two months. There was an increased friability value for most tablets. Tablets produced by slugging stored at ambient humidity were more friable than those produced by melt granulation. They exhibited an increased from $1.09 \%$ to $2.31 \%$ after one month and then slightly decreased to $2.09 \%$ after the second month. While the friability of tablets produced using carnauba wax increased continuously from first and second month. At $2 \%$ carnauba wax concentration, the friability increased from $2.98 \%$ to $3.20 \%$ after the first month of storage and to $3.30 \%$ after the second month. Tablets containing goat fat increased in friability and remained constant. At $1 \%$ goat fat concentration, the friability increased from 3.08\% to $3.20 \%$ after first month and remained same even after the second month (TABLE 3). However, tablets containing carnauba wax which were stored at $0 \%$ relative humidity exhibited a slight decrease after the second month. Their friability decreased from 1.38 to $1.35 \%$ at $5 \%$ carnauba wax concentration and from 1.35 to $1.32 \%$ at $7.5 \%$ concentration (TABLE 4).

A slight decrease in tablet tensile strength was observed after storage with the exception of tablets containing goat fat, which showed no change when stored at $1 \%$ relative humidity. Before and after storage the tensile strength remained at $0.02 \mathrm{NMm}^{-2}$ (TABLE 4). The decrease in tensile strength was more pronounced for all tablets stored at ambient humidity. A decrease from 0.04 to $0.02 \mathrm{MNm}^{-2}$ was observed for tablets containing carnauba wax ( 2 and $3 \%$ concentration) and 0.07 to $0.06 \mathrm{MNm}^{-2}$ for tablets produced by slugging (TABLE 3).

After storage of tablets at ambient and $1 \%$ relative humidity for two months, a decrease in the disintegration time was observed for all tablets. A decrease from 5.04 to 3.25 min was observed for tablets produced with goat fat $(2 \%)$ that were stored at ambient humidity. Also tablets containing carnauba wax $(2 \%)$ had their disintegration time reduced from 5.30 to $4.08 \mathrm{~min}$. Slugged tablets showed a decrease from 3.50 to $0.42 \min$ (TABLE 3 ). 
TABLE 1: Flow and packing properties aspirin granules

\begin{tabular}{|l|l|l|l|l|l|l|}
\hline $\begin{array}{l}\text { Type and } \\
\text { concentration of wax } \\
(\% \mathrm{w} / \mathrm{w})\end{array}$ & $\begin{array}{l}\text { Tapped density } \\
\left(\mathrm{g} / \mathrm{cm}^{3}\right) \pm \mathrm{SD}\end{array}$ & $\begin{array}{l}\text { Bulk density } \\
\left(\mathrm{g} / \mathrm{cm}^{3}\right) \pm \mathrm{SD}\end{array}$ & $\begin{array}{l}\text { Angle of repose } \\
\left({ }^{\circ}\right) \pm \mathrm{SD}\end{array}$ & $\begin{array}{l}\text { Carr's index } \pm \\
\text { SD }\end{array}$ & $\begin{array}{l}\text { Hausner's ratio } \pm \\
\text { SD }\end{array}$ \\
\hline Goat fat & 1.0 & $0.80 \pm 0.00$ & $0.63 \pm 0.02$ & $27.57 \pm 0.67$ & $21.88 \pm 0.01$ & $1.28 \pm 0.11$ \\
wax & 2.0 & $0.78 \pm 0.02$ & $0.62 \pm 0.00$ & $39.21 \pm 0.59$ & $20.53 \pm 0.59$ & $1.26 \pm 0.08$ \\
\hline Carnauba & 2.0 & $0.85 \pm 0.00$ & $0.71 \pm 0.01$ & $33.77 \pm 0.42$ & $16.07 \pm 0.23$ & $1.19 \pm 0.05$ \\
wax & 3.0 & $0.82 \pm 0.01$ & $0.71 \pm 0.01$ & $31.40 \pm 0.43$ & $13.27 \pm 0.15$ & $1.15 \pm 0.10$ \\
& 5.0 & $0.80 \pm 0.00$ & $0.70 \pm 0.03$ & $29.06 \pm 0.14$ & $12.50 \pm 0.07$ & $1.22 \pm 0.06$ \\
& 7.5 & $0.77 \pm 0.02$ & $0.69 \pm 0.04$ & $26.96 \pm 0.07$ & $10.34 \pm 0.14$ & $1.12 \pm 0.05$ \\
\hline $\begin{array}{l}\text { Granules } \\
\text { by }\end{array}$ & 0.0 & $0.82 \pm 0.00$ & $0.66 \pm 0.01$ & $35.91 \pm 0.44$ & $19.51 \pm 0.07$ & $1.24 \pm 0.08$ \\
slugging & & & & & & \\
\hline
\end{tabular}

TABLE 2: Physical properties of tablets before storage

\begin{tabular}{|l|l|c|c|c|}
\hline \multicolumn{2}{|l|}{$\begin{array}{l}\text { Type and concentration } \\
\text { of wax }(\% \mathrm{w} / \mathrm{w})\end{array}$} & Friability (\%) \pm SD & $\begin{array}{c}\text { Tensile strength }\left(\mathrm{MNm}^{-2}\right) \pm \\
\text { SD }\end{array}$ & Disintegration time (min) \pm SD \\
\hline Goat fat & 1.0 & $3.08 \pm 0.04$ & $0.02 \pm 0.01$ & $2.28 \pm 0.12$ \\
& 2.0 & $3.10 \pm 0.01$ & $0.02 \pm 0.00$ & $5.04 \pm 0.08$ \\
\hline Carnauba & 2.0 & $2.98 \pm 0.10$ & $0.04 \pm 0.01$ & $5.30 \pm 0.13$ \\
& 3.0 & $2.23 \pm 0.03$ & $0.04 \pm 0.00$ & $5.02 \pm 0.09$ \\
& 5.0 & $1.38 \pm 0.01$ & $0.05 \pm 0.01$ & $4.29 \pm 0.15$ \\
& 7.5 & $1.35 \pm 0.04$ & $0.05 \pm 0.01$ & $3.02 \pm 0.08$ \\
\hline Tablets by & 0.0 & $1.09 \pm 0.05$ & $0.07 \pm 0.00$ & $3.50 \pm 0.14$ \\
slugging & & & & \\
\hline
\end{tabular}

TABLE 3: Effect of ambient humidity on the Physical properties of aspirin tablets

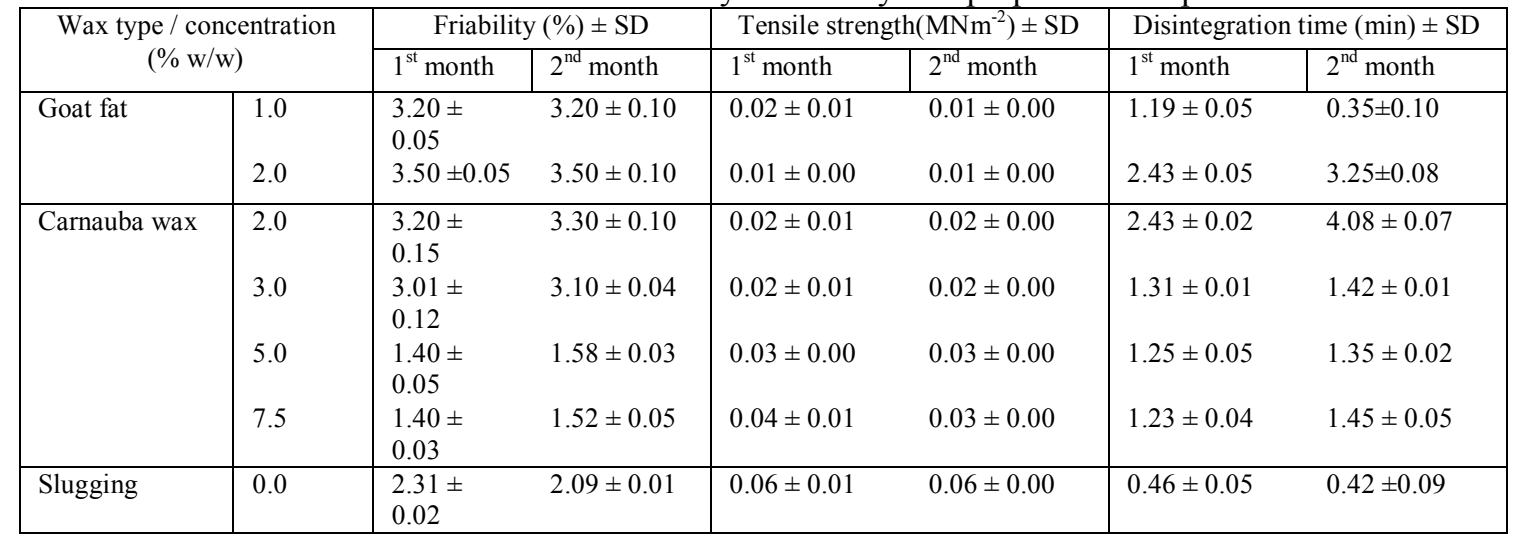

TABLE 4: Effect of relative humidity (RH 0\%) on the physical properties of aspirin tablets

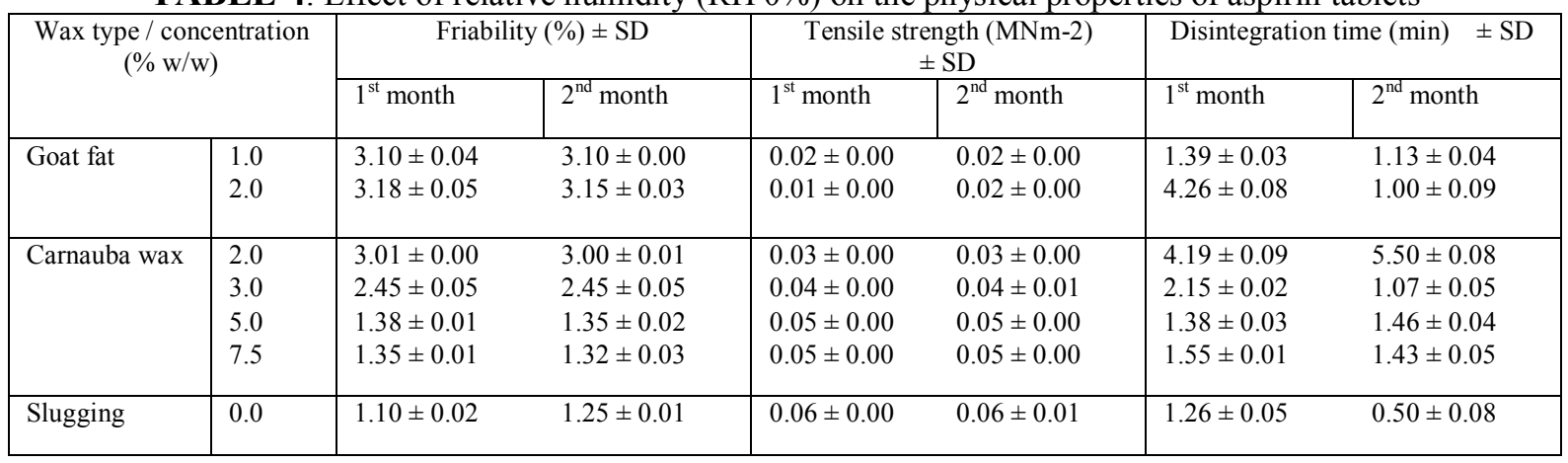




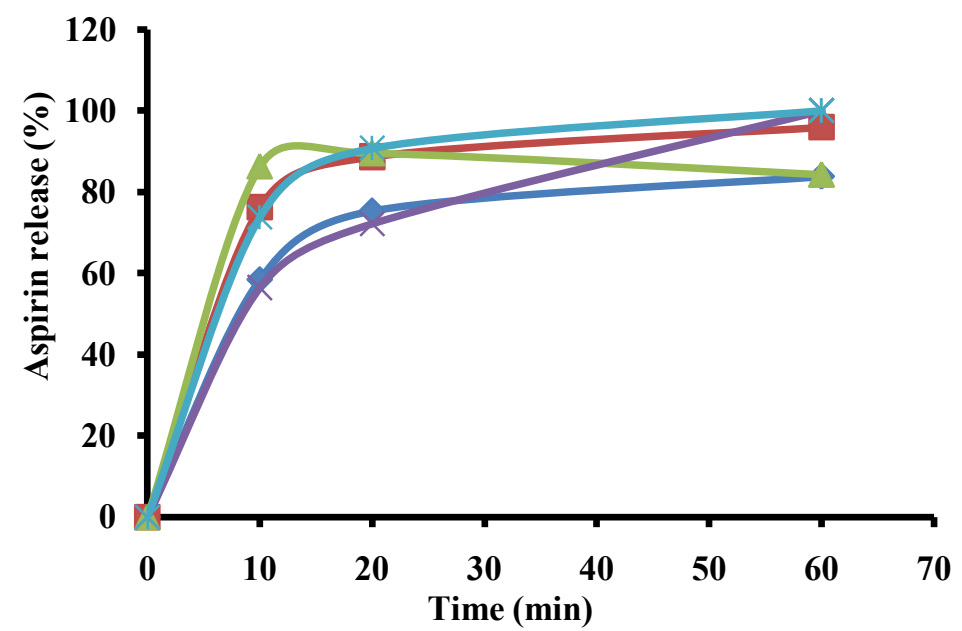

Figure 1: urug reıease promıe or aspırın tabıets proaucea py sıugging (") ana by melt granulation with carnauba wax: $2 \%(\diamond), 3 \%(\bullet), 5 \%(\triangle)$ and $7.5 \%(x)$

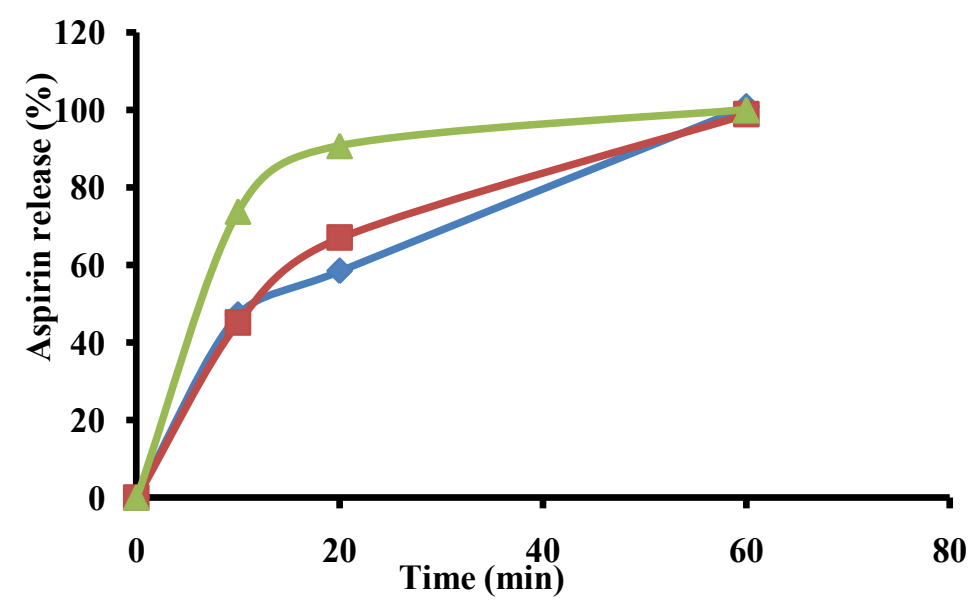

Figure 2: Drug release profile of aspirin tablets produced by slugging $(\triangle)$ and by melt granulation with goat fat (४) and $2 \%(\square)$

\section{Conclusion}

Melt granulation technique, which is considered a simpler and cheaper method produced aspirin tablets with better physical stability than aspirin tablets produced by slugging when stored under ambient humidity and $1 \%$ relative humidity. Despite the fact that waxes are hydrophobic in nature, tablets disintegration and dissolution properties were not impaired. Carnauba wax even improved the flow and packing properties of the resulting granules.

\section{Reference}

[1] H.D. Lewis, J.W. Davis, D.G. Archibald, W.E. Steinke, T.C. Smitherman, J.E. Doherty, H.W. Schnaper, M.M. LeWinter, J.W. Pouget, S.C. Sahlarwal, E. Chesler, H. Demots. Protective effects of aspirin against acute myocardial infarction and death in men with unstable angina. Results of a veteran administration co-operative study. The New England Journal of Medicine; 309: 1983, 396403.

[2] D.G. Julian, D.A. Chamberlain, S.J. Pocock. A comparison of aspirin and anticoagulation following thrombolysis for myocardial infarction (the AFTER study): a multi centre un-blinded randomized clinical trial. British Medical Journal; 313(7070): 1996, 1429 1431

[3] M.P. Rothwell, P.M. Wilson, F. Jacqueline, J. Belch, T.W. Meade, Z. Mehta. Effect of daily aspirin on risk of cancer metastasis: A study of incident cancers during randomized controlled trials. The Lancet; 6736: 2012, 60208 - 60209.

[4] A.M. Algra, P.M. Rothwell. Effects of regular aspirin in long term cancer incidence and metastasis: A systematic comparison of evidence from observational studies versus randomized trials. The Lancet Oncology, 10(12), 2012, 70-112.

[5] T. Schaefer, P. Holm, H.G. Kristensen. Melt granulation in a laboratory scale high shear mixer. Drug Development Industrial Pharmaceutics; 16: 1990, 1249-1277.

[6] N.V. Patel, N.P. Chotai, M.P. Patel. Formulation design of oxycarbamazepine fast release tablets prepared by melt granulation technique. Asian Journal of Pharmaceutics; 2: 2008, 22 - 25.

[7] J.A. Avbunudiogba, R.S. Okor, M.U. Uhumwangho, M.I. Arhewoh. Melt granulation of aspirin powder as an alternative to slugging: Implication for compressibility and dissolution rate. Nigerian Journal of Pharmaceutical Sciences, 11(1), 2012, 32-39. 
[8] B. Perissutti, F. Rubessia, M. Moneghini. Formulation design of carbamazepine fast release tablets prepared by melt granulation. International Journal of Pharmaceutics; 256: 2003, 53-63

[9] A.T. Saadia, I.S. Iman, L. Dina. Formulation of ketotifen fumarate fast melt granulation sublingual tablet. American Association of Pharmaceutical Scientists; 11:2010, 679-685

[10] N. Passerini, B. Albertini, M.L. Gonzalez-Rodrigue, C. Cavallari, L. Rodrigue). Preparation and characterization of ibuprofen poloxamer-188 granules obtained fr om melt granulation. European Journal of Pharmaceutical Sciences; 15: 2002, 71-78.

[11] R. Chokshi, H. Zia. Hot melt extrusion technique: A review. Iranian Journal of Pharmaceutical Research; 3: 2004, 3-16.

[12] A. Nokhodchi, Y. Javadzadeh. The effect of storage conditions on the physical stability of tablets. Pharmaceutical Technology, Europe, 19(1), 2007

[13] E.I. Okoye, A.O. Onyekweli, O.O. Kunle. Brittle fraction index (BFI) as a tool in the classification, grouping and ranking of binders in tablet formulation: Paracetamol tablets. International Journal of Applied Biology and Pharmaceutical Technology, 3 (2): 2012, 261-271.

[14] A.O. Onyekweli. Adaptation of Erweka Tablet friabilator for Tap density measurement. West African Journal of Pharmacy, 14: 2000, 74 - 78 . 